\title{
Democracia y régimen de partidos en México en la perspectiva latinoamericana
}

\author{
Ilán Bizberg*
}

Resumen: Este artículo discute el hecho de que la democracia de procedimiento en las nuevas democracias, como las que existen en América Latina, ha encontrado importantes limitaciones, que conciernen fundamentalmente el que la población pobre tenga un acceso limitado a la esfera pública donde se definen las elecciones. En algunos países latinoamericanos se han intentado formas de democracia participativa para paliar este limitante; con particular éxito en Brasil. También han existido sistemas políticos democráticos con un bajo nivel de representatividad, como el que existió en Venezuela, hasta Chávez. Es por ello que para analizar los distintos tipos de régimen que existen en páses particulares proponemos un esquema que no solo considere la consolidación de los partidos políticos, sino el nivel de representatividad del sistema político y el grado de densidad de la organización de la sociedad civil. Con este instrumento, el artículo analiza el caso mexicano.

Palabras-clave: Democracia, Representación, Participación, Sociedad Civil, México.

Abstract: This article discusses the fact that procedural democracy in new democracies, such as those existing in Latin America, has met crucial limitations, fundamentally concerning the fact that the poor population has limited access to the public sphere that defines elections. In some Latin-American countries different schemes of participatory democracy have been tried in order to compensate this limitation; with particular success in Brazil. There have also existed democratic political systems with low level of representation, such as the one of Venezuela, before Chavez. That is why in order to analyze the different types of regime existing in singular countries we propose a scheme that not only considers the consolidation of political parties but the level of representation of the political system and the density of the organization of civil society. With this instrument, this article analyses the Mexican case.

Keywords: Democracy, Representation, Participation, Civil Society, Mexico.

\footnotetext{
* Centro de Estudios Internacionales - El Colegio de México. E-mail: ilan@colmex.mx. Recebido em 06/02/07 e aceito em: 11/06/07.
} 


\section{Las fallas estructurales de las democracias latinoamericanas}

La mayor parte de los observadores de la vida política de los países latinoamericanos consideran que nuestras jóvenes democracias aún tienen graves deficiencias. Algunos autores, como Przeworski, explican esto como el desencanto natural que produce la política, en especial en países de reciente democratización. La idea de la democracia viene acompañada de grandes esperanzas, se piensa que va a resolver todos los problemas, y cuando finalmente llega, no sólo no los resuelve, sino que vemos cómo la política se reduce a estrategias partidistas de corto plazo, transacciones y concesiones pragmáticas, tácticas dilatorias, bloqueos de un partido a otro, muy alejados de los grandes proyectos programáticos e ideológicos de las campañas. (O’DONNELL, SCHMITTER, 1986, p. 90-91).

Es por ello que algunos autores han optado por defender un concepto mínimo de democracia, con el sentimiento de que mientras más se le pida a la democracia, mayor será la decepción y más se debilitara a la propia democracia. De esta manera, la concepción mínima de democracia que se ha adoptado es la que Dahl llama poliarquía, que consiste en: elecciones libres y universales, que los puestos públicos sean accesibles a todos, que todos los individuos tengan la libertad de militar en las organizaciones políticas y sociales, y finalmente que los actores clave de la sociedad (los partidos políticos, los militares, los empresarios) consideren que las elecciones son la única vía para llegar al poder (DAHL citado por DIAMOND, LINZ, LIPSET, 1995, p. 6-7).

No obstante, esta concepción mínima, procedimental de la democracia, no reconoce las fallas estructurales de la democracia como procedimiento, que se agudizan en la época actual de mutación de la sociedad industrial hacia la sociedad de la información, cuando los actores de la sociedad industrial están en declive. Existen, además, fallas estructurales específicas de las democracias latinoamericanas. Estas últimas están bien resumidas por O’donnell con base en tres conceptos: Particularismo, democracia delegativa y falta de rendición de cuentas horizontal. El particularismo se refiere a que si bien los políticos llegan al poder por medio de elecciones cada vez más vigiladas y abiertas, en muchas ocasiones no hacen la diferencia entre su interés particular-individual y el puesto público-universal al que han accedido; de ahí que la vida política 
latinoamericana esté plagada de corrupción y nepotismo (O’DONNELL, 1996, p. 80). Amplios sectores de la población también están imbuidos de este mismo carácter particularista: las elecciones deben resultar en mejoras a su situación particular; lo que lleva a que la política en nuestros países, en los que una parte considerable de la población vive en la pobreza, esté en gran parte fundada en el clientelismo, en el intercambio de votos por favores.

Esto se relaciona con el concepto de democracia delegativa. La población da un cheque en blanco a sus políticos, para que gobiernen como mejor les parezca una vez que llegan al poder. Esto se traduce en una insuficiente rendición de cuentas. Por una parte, los gobernantes consideran que se les ha otorgado la facultad de gobernar como les parezca conveniente, y consideran que su proyecto debe someterse a la menor resistencia posible. Esto los lleva a obstaculizar cualquier intento de creación de instancias de rendición de cuentas y a debilitar o destruir las que existen. Si bien es cierto que las elecciones son una forma de exigir cuentas a los gobernantes, es una forma de hacerlo a posteriori: se castiga a quienes han gobernado de manera abusiva o ineficaz (O’DONNELL, 1996, p. 87). No obstante, hay pocas instancias horizontales que vigilen a los gobernantes mientras están en el poder, que controlen su acción. Las pocas instancias capaces de vigilar a los gobernantes y publicitar los abusos de poder (como la prensa, las comisiones de derechos humanos, algunas ONG's), pocas veces tienen la capacidad de sancionar a los que incurren en ellos, lo que va en contra de la democracia en la medida en que aumenta el desencanto (O’DONNELL, 1998, p. 119).

De esta manera, resume O'donnell, la democracia en nuestros países cumple mal con sus dos dimensiones, la republicana y la liberal. La republicana que enfatiza la separación entre el ámbito de lo público y lo privado está poco desarrollada. La liberal, porque, en nuestros países, pocos individuos son verdaderos ciudadanos; los abusos del poder son muy frecuentes y afectan mayoritariamente a los sectores más pobres. El único momento en que la mayoría de los individuos de nuestras jóvenes democracias ejercen un derecho cívico es cuando votan (O’DONNELL, 1998, p. 113). 


\section{Grados de institucionalización de los regímenes políticos}

La perspectiva que considera las elecciones como la base de la democracia propone que estas fallas pueden resolverse si existe un e de partidos institucionalizado. Es por ello que Mainwaring y Scully (1995) han tratado de medir el grado de esta institucionalización, con base en “...la estabilidad en la competencia entre los partidos, la existencia de partidos que tienen un enraizamiento relativo en la sociedad, la aceptación de los partidos y de las elecciones como las instituciones que determinan quien gobierna $y$, finalmente, que existan partidos con estructuras y reglas razonablemente estables" (MAINWARING, SCULLY, 1995, p. 1) Esta clasificación permite cuantificar el grado de institucionalización de regímenes partidistas y situarlos en un continuo definido por los casos extremos. Existirían tipos institucionalizados de partidos, como el chileno, pero también el uruguayo y el costarricense. Por otra parte, habría regímenes de partidos des-estructurados como los de, Perú, Ecuador, Bolivia y hasta muy recientemente Brasil. ${ }^{1}$

Es evidente que este esquema sea útil para definir a los regímenes en los extremos. El caso chileno se ha caracterizado por una impresionante estabilidad. A partir de la transformación democrática hemos visto como se han mantenido dos coaliciones políticas. Los partidos políticos están bien estructurados en torno a proyectos, programas y no personalidades. Por otra parte, los partidos políticos chilenos se caracterizan por reglas claras para elegir a sus candidatos y una relación muy estrecha entre los funcionarios electos y los partidos que los postularon. Es conocido el arraigo que siempre tuvieron los partidos políticos en la sociedad chilena, que crearon verdaderas subculturas políticas: en especial entre los sindicatos y los partidos socialista y comunista. Aunque también es cierto que éste sea uno de los rasgos que están ausentes del actual régimen partidista chileno (TIRONI, AGÜERO, 1999, p. 66; ANGELL, 2004, p. 12).

En contraste, en regímenes volátiles o incoherentes, partidos que son importantes en una elección aminoran radicalmente su votación en la siguiente, o de plano desaparecen. Los partidos frecuentemente giran en

\footnotetext{
${ }^{1}$ Brasil era hasta hace poco tiempo uno de los regímenes menos institucionalizados, como lo atestigua la mayor parte de la literatura. No obstante, es posible encontrar desde hace algunos años signos de institucionalización en el hecho de que el régimen partidista se está estructurando alrededor de dos ejes, el PT y el del PSDB.
} 
torno a personalidades, o son sencillamente creados por un liderazgo en vista de una elección. Hay poca disciplina de partido: los diputados se pasan de un partido a otro una vez que llegan al Congreso, frecuentemente emiten un voto contrario a su partido. Esto tiene como consecuencia no solo la corrupción y el clientelismo, sino la poca capacidad de rendición de cuentas; los electores pocas veces pueden identificar a un candidato con su partido, en general sólo votan por personalidades, lo que no permite a los partidos ejercer ningún control sobre ellas. Esto se acentúa cuando los candidatos cambian tan fácilmente de partido, o los partidos simplemente desaparecen al perder el apoyo del líder (MAINWARING, SCULLY, 1995, p. 108, p. 107-119; KINZO, 2001, p. 38). Hasta hace poco tiempo, el régimen de partidos brasileño era conocido por su volatilidad, al igual que el peruano, ecuatoriano y el boliviano. Aunque esto está cambiando en Brasil, con la aparición del PT, su régimen partidista aún conserva muchos de los rasgos de este tipo.

La idea detrás de la elaboración de un instrumento que mida la institucionalización de los partidos políticos es que mientras más consolidados estén los partidos, sea más factible llamar a cuentas a los dirigentes: partidos que tienen un prestigio y una clase política que defender, pueden ejercer mayor control sobre sus funcionarios electos; lo que también significa que son más responsables. En contraste, regímenes poco institucionalizados y personalizados son menos controlables por el propio partido y por el propio electorado. Una ciudadanía con partidos afianzados, representativos y enraizados en la sociedad está menos tentada a ser arrastrada por figuras carismáticas o movimientos radicales de ruptura. Tiene asimismo menor tendencia a dar un cheque en blanco a sus dirigentes, aceptar delegar el poder o a que algunos de sus sectores de la población puedan considerar admisible el arribo al poder por vías distintas a las elecciones.

\section{La democracia más allá de las elecciones}

Si bien la categorización elaborada por Mainwaring y Scully (1995) permite ubicar algunos países en los extremos, no obstante es muy pobre para describir a los que se encuentran en medio del continuo; como México, o Argentina y tantos más. Tampoco está muy claro si estos países se alejan efectivamente de 
los peligros que aquejan a las nuevas democracias. Realmente, tampoco nos permite analizar a algunos de los regímenes de partidos que se encontraban institucionalizados, como Venezuela o Colombia. Estos dos países tuvieron regímenes partidistas muy estables e institucionalizados durante mucho tiempo, lo que no evitó que hayan sido destruidos en los últimos años y hayan sucumbido, por lo menos en lo que corresponde a Venezuela, en un gobierno delegativo.

Es por ello que hace falta profundizar en los criterios que definen la consolidación de un régimen de partidos. Es necesario alejarse de la perspectiva normativa, según la cual ciertos criterios acercan o alejan a un país del ideal democrático. Hay que establecer, por el contrario, tipologías de regímenes partidistas a los que los países reales se acercan.

Para construir las tipologías considero no solamente al régimen partidista, en lo que respecta a su estabilidad y coherencia, sino que subrayo con la misma fuerza la relación "afectiva" de los sujetos (ya sean ciudadanos individuales o actores colectivos) con respecto al régimen de partidos, es decir su representatividad. Ésta se refiere a la capacidad que tienen los partidos de reflejar las identidades, los intereses y los proyectos de la población tomada individualmente, así como con respecto a los distintos sectores que conforman a la sociedad. Por una parte, la población tiene en cuenta si los partidos políticos abordan los problemas y los proyectos que la conciernen. Una población que no lo considera así, podría tender a aceptar un régimen sin elecciones pero que mejore su condición. Probablemente se abstendrá en las elecciones o votará nulo o blanco, o por partidos que no entran al Congreso. Lo que significa que existe una población disponible para líderes carismáticos o movimientos de ruptura. En lo que respecta a los grupos o actores colectivos, la pregunta es si los grupos más relevantes: la clase empresarial, las clases asalariadas, los pobres y marginados (cuando estos son mayoría como en nuestros países), cuentan con partidos políticos que los representen y que obtengan las instancias de poder y de decisión. Si la respuesta es negativa, es posible que estos individuos o grupos estén tentados a dudar que las elecciones son el único camino para decidir quien gobierna.

El otro elemento que es necesario considerar es la organización de la sociedad civil. Este es un tema clásico de la filosofía política y de la teoría 
de la democracia. Tocqueville consideraba que las "enfermedades" de la democracia se curaban profundizándola, democratizando a la democracia. En el ejemplo de los EEUU vio que lo que cimentaba a la democracia era la organización de la sociedad civil (TOCQUEVILLE, 1981, T.1, p. 278; T.2, p. 137). Habermas, por su parte, considera que la sociedad civil es la mediación necesaria entre el individuo y la sociedad política, el ámbito en el cual se expresan, concentran y dramatizan las demandas, deseos y proyectos de los distintos grupos e intereses que conforman a la sociedad. Es la sociedad civil la que enuncia los problemas que el sistema político debe resolver. Es ella una manera de asegurar y aumentar la representatividad del sistema político. (HABERMAS, 1997, p. 394) Una sociedad organizada no sólo erige los límites al poder del Estado, como pensaba Tocqueville, sino que permite vigilar a los funcionarios, exigirles que cumplan con su función. Más que enraizamiento de los partidos políticos en la sociedad civil, como se ve la cuestión desde la perspectiva de los primeros, lo que es necesario analizar es la capacidad de la sociedad civil de manifestar, canalizar y expresar de manera dramática las demandas, los intereses y los proyectos de los distintos sectores de la población.

De esta manera, la organización de la sociedad civil puede resolver algunos de los problemas más profundos que mencionamos arriba: la falta de rendición de cuentas y la delegación del poder. El asociarse, le permite a los individuos vigilar al poder y participar en las decisiones que toman los políticos. Abre, además, la posibilidad de que los partidos políticos se enraícen en ella, haciéndolos más representativos (TOURAINE, 1994, p. 98).

\section{Hacia una tipología de los regímenes políticos}

Es necesario construir un esquema que incluya las tres dimensiones de las que hemos estado hablando: institucionalización del régimen de partidos, representatividad y organización de la sociedad civil tendríamos un cubo con una configuración institucional distinta en cada uno de los vértices, es decir con ocho distintos tipos de régimen de partidos. 


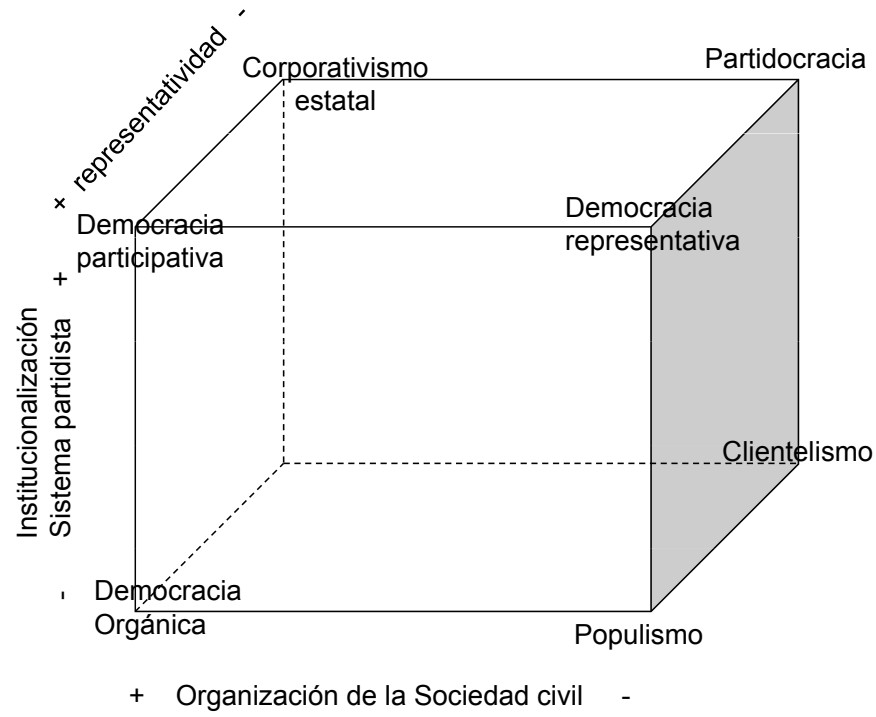

Figura 1 - Esquema 5.1 - Tipología de los regímenes partidistas

De esta manera, no tendríamos un solo tipo de configuración partidista democrático, un solo modelo de democracia ideal, sino por lo menos siete ${ }^{2}$ distintas configuraciones que podríamos considerar que respetan la forma democrática, en el sentido de que llevan a cabo elecciones, pero cuyas características y, por decirlo así, su calidad, difieren profundamente. Por otra parte, es bastante claro que los regímenes que se encuentran en el lado posterior del cubo, que tienen poca representatividad, son poco democráticos; en algunos casos sólo cumplen con las formas democráticas mínimas. Este esquema integra, además, la temporalidad, el cambio, en la medida en que los regímenes políticos particulares tienen una trayectoria específica al interior del cubo. Por otra parte, hay que aclarar que este esquema define tipos ideales que no coinciden con ninguna configuración real de régimen político, que

\footnotetext{
${ }^{2}$ Considero que uno de los vertices está vacio, el que combina baja representatividad y fuerte organización de la sociedad civil, con una baja institucionalización del régimen partidista. Porque mientras que si consideramos la alta institucionalización del régimen partidista podemos concebir a un régimen de corporativismo estatal que cuenta con un partido político que aglutine a las corporaciones, como fue el caso mexicano, el caso contrario me parece poco razonable.
} 
los regímenes reales se acercan más o menos a estos tipos ideales y que en general tienen características de varios de ellos, por lo que visto gráficamente se encontrarían en el interior del cubo más que en los vértices.

Si adoptamos la perspectiva desde el eje de la institucionalización de un régimen de partidos, tendríamos cuatro regímenes partidistas con distinto grado de representatividad y diferente nivel de organización de la sociedad civil. En uno de los vértices del cubo estaría la democracia representativa, mientras que en el otro la democracia participativa, ambas con un nivel alto de representatividad. Del lado posterior del cubo están dos regímenes con poca representatividad, aunque con un nivel alto de institucionalización del régimen de partidos. Por una parte, el corporativismo estatal, en el cual los partidos representan a las distintas corporaciones en las que se estructura la sociedad, cuanta con poca representatividad en tanto que los partidos representan intereses específicos que se han "coagulado" y burocratizado con el tiempo y que deja a cada vez más grupos fuera del esquema de representación. Una situación que se acerca a esta forma es el régimen priísta mexicano, de partido hegemónico. Otro tipo de régimen institucionalizado, pero también poco representativo es la partidocracia; en la cual los partidos han creado un régimen que les permite reproducirse y eventualmente perpetuarse en el poder, limitando el surgimiento de otros partidos o asociaciones; lo que tiene asimismo como consecuencia que buena parte de la sociedad quede sin representación. Una situación particular que se acerca a este tipo es la Venezuela anterior a la llegada de Chávez.

En la base inferior del cubo se encuentran los tipos de régimen partidista con partidos políticos poco institucionalizados. Uno de ellos es el tipo ideal del clientelismo, en cual los individuos se relacionan con el gobierno por intermediarios, "brokers", quienes más que representarlos "venden" servicios y bienes a cambio de lealtad política. Es posible construir un régimen de partidos sobre esta base, especialmente si existe un sistema electoral muy abierto a la creación de nuevos partidos, con límites muy bajos para que un partido llegue al Congreso y con listas electorales abiertas. Este tipo de sistema electoral favorece la personalización de la política electoral, que ha sido frecuente en varios países Latinoamericanos y permiten un régimen 
poco representativo, como el clientelismo. ${ }^{3}$ El populismo es la imagen especular del clientelismo, aunque está basado en una relación muy similar entre el gobierno y los individuos. No obstante, como lo plantea Laclau, el populismo está basado en un profundo clivaje de la sociedad, en su división en sectores absolutamente incluidos y beneficiados y otros absolutamente excluidos, representados por un liderazgo carismático. Este último representa a los individuos del pueblo desposeído ${ }^{4}$ sin mediaciones, sin necesidad de partidos y organización social. Los individuos aislados tienen una relación afectiva con él. En ocasiones, una vez establecido el régimen populista, el propio gobierno estimula la organización social y organiza a la sociedad de manera poco autónoma, e intenta convertirlo en un régimen corporativo; aunque pocos han logrado este pasaje de manera tan eficaz, como el mexicano. Está, por último, otro régimen con poca institucionalización de los partidos y alto nivel de representatividad, que he denominado democracia orgánica. Este es un régimen basado en la representación nacional, étnica, o tribal. Existen pocos ejemplos nacionales de este régimen, que podemos considerar como adecuados. Quizá un país como Afganistán, que se gobierna a nivel nacional con base en la organización de clanes es un caso. Las otras situaciones que podríamos asimilar a este tipo son locales: las regiones o las localidades que se gobiernan con base en los usos y las costumbres comunitarias, por ejemplo algunas de las comunidades indígenas del Sur de México, en Oaxaca.

\section{El caso de México en perspectiva comparada}

\section{El régimen partidista}

¿Cómo nos sirve este esquema para entender el caso mexicano en un contexto comparativo? La primera de las dimensiones que definen a los regímenes partidistas es la institucionalización de los partidos. Por razones evidentes, el régimen de partido hegemónico, el autoritarismo priísta, fue

\footnotetext{
${ }^{3}$ Es cierto que esta era una de las características del sistema electoral de Brasil, que sin embargo está cambiando, básicamente por el fortalecimiento del PT, que es un partido más moderno, no clientelar. Recientemente se ha modificado la legislación electoral y se ha fijado un porcentage mínimo para tener una representación en el Congreso, del 2\% de los votos y en por lo menos 9 unidades de la federación. Página web: eleicoes.uol.com.br/2006/reportagens/clausula.jhtm

${ }^{4}$ En la definición romana de la plebe.
} 
un régimen muy estable. El régimen era estable por la relación especial entre el PRI y la sociedad. El PRI logró erigirse en el abanderado de los ideales de la Revolución mexicana y construir un entramado social con base en el fortalecimiento de los sindicatos y en el reparto agrario durante la presidencia de Cárdenas (1934-1940). Fue una alianza entre el Estado y los grupos populares, que derivó cada vez más en una relación corporativa-clientelar, de intercambio entre favores y apoyo político. De esta manera, la sociedad fue subordinada a los partidos; los actores que cuestionaban este arreglo eran marginados o reprimidos. De esta manera, si bien es cierto que la sociedad estaba organizada, lo estaba bajo las reglas y el dominio del Estado, no era autónoma (BIZBERG, 1999, 2003).

La democratización mexicana se produce básicamente por la vía electoral. Y en esa transformación, los partidos políticos de oposición, el PAN y el $\mathrm{PRD}$, así como las organizaciones de la sociedad civil que luchan por mayor transparencia en las elecciones y la creación de instituciones independientes del Estado que las vigilen, son los protagonistas principales. Este proceso por el que pasa nuestro país, en el cual un partido hegemónico es derrotado por la oposición, se parece más al proceso por el que pasan algunos países comunistas que a la democratización de los países de América Latina. En estos últimos, los militares son obligados a regresar a sus cuarteles y retornan los partidos anteriores a los golpes (Chile, Uruguay, Argentina) o se crean nuevos (Brasil). En la mayoría de los países de Europa del Este, el nuevo escenario partidista comprende una serie de nuevos partidos políticos que surgen en el proceso de democratización y un partido post-comunista.

Mientras que en la mayoría de los países de América latina y en algunos de Europa Central y del Este, esta situación ha dado lugar a un régimen partidista muy volátil y personalizado (Brasil, Perú, Ecuador y Polonia. En otros países (Chile, la República Checa, Hungría, y en cierta medida en Argentina) ha surgido un régimen de partidos políticos bastante consolidados. A Chile lo gobierna una coalición desde hace 17 años. Argentina ha sido gobernada por los partidos Unión Cívica Radical ${ }^{5}$ y justicialista desde que retornó a la democracia.

En lo que se refiere a la dimensión de institucionalización, el régimen

${ }^{5}$ Durante la presidencia del depuesto De la Rua, el partido radical gobernó en alianza con el FREPASO. 
partidista mexicano parece bastante estable. Existen tres partidos solidamente establecidos, que han dominado la escena partidista desde hace varias décadas. Los tres son partidos con reglas relativamente bien establecidas. El antiguo partido dominante es un partido importante, aunque ha caído al tercer lugar en número de diputados en el Congreso, aún gobierna $17^{6}$ de los estados y la mayoría de los municipios. Los otros dos partidos principales, el PAN y el PRD, tienen respectivamente 67 y 19 ańos. Por su parte, el electorado ha sido bastante estable hasta el momento actual, el índice de volatilidad electoral es del 16,9\%, relativamente baja si se la compara con otros países de América Latina: el promedio para el continente es del 23,2\%, algunos países como Bolivia, Guatemala, Perú, Venezuela, están a niveles mayores del 30\%, e incluso del 40\% en el caso de Perú (PNUD, 2004, p. 71). Esto parece reflejar el hecho de que existe un núcleo duro de electores para cada partido y que las elecciones se deciden por aquellos que no son sus simpatizantes, como es el caso en las democracias consolidadas. En gran medida, los ciudadanos mexicanos son capaces de reconocer las diferencias entre los distintos partidos y candidatos. Por otra parte, la ley electoral establece un límite inferior relativamente elevado para que los partidos obtengan el registro definitivo ( $2 \%$ de la votación) y consigan una representación en el congreso, lo que evita la fragmentación del sistema de partidos y su personalización.

Existen, no obstante, algunos signos que apuntan hacia una posible desinstitucionalización del régimen partidista. Hay, por un lado, una transferencia constante de personal político entre los partidos, sobretodo del PRI al PRD, pero también del PRI al PAN. Esto se ha producido en respuesta a no ser electo por su partido como candidato para un puesto político. No obstante, en México no se produce aún la deserción masiva de diputados como sucede en Brasil o en las nuevas democracias de Europa Central.

Uno de los mayores problemas de los regímenes partidistas en Latinoamérica y de algunas de las nuevas democracias se refiere a la segunda de las dimensiones con las que definimos los regímenes de partido: la representatividad. Como lo hemos dicho, en muchos países de América Latina, los partidos se crean para apoyar las ambiciones políticas de un personaje. En los países de Europa Central y del Este, algunos de los partidos

\footnotetext{
${ }^{6}$ Hay en total 31 estados y un distrito federal, que también elige a su jefe de gobierno por votación universal.
} 
surgen con base en clivajes étnicos y demandas nacionalistas. Mientras que el personalismo contribuye a dificultar la rendición de cuentas y, en muchos casos, crea partidos poco representativos. En el segundo, si bien existe un grado importante de representatividad, los partidos representan una especie de guerra civil larvada. Muchos de los autores que estudian los partidos de las nuevas democracias en los países de Europa del Este plantean para consolidar su régimen de partidos hace falta que éstos reflejen las divisiones de la sociedad, más que las divisiones étnicas o nacionales (O’DWYER, 2004, p. 549).

Por un lado, las nuevas democracias se enfrentan a la misma problemática que domina la vida política de las viejas democracias, el declive del conflicto central de la sociedad industrial: entre trabajadores y empresarios y la falta de surgimiento del nuevo régimen basado en los conflictos que caracterizan a la sociedad de la información. Pero a lo que también se hace referencia es a la falta de arraigo del sistema político en la sociedad, por la debilidad de la organización autónoma de ésta.

A pesar de ello, es posible decir que en algunas nuevas democracias se ha creado un régimen de partidos relativamente representativo de los sectores sociales centrales. Es posible afirmar que el régimen de partidos chileno es uno de los pocos en el continente que ha logrado representar a uno de los sectores que apoyó el rompimiento del orden institucional en ese país y en otros de América latina; las clases empresariales y medias altas (BARRETT, 2000, p. 24; ANGELL, 2004, p. 14). Por el lado de la izquierda, el último gobierno de la coalición en Chile, así como el actual, han defendido la idea de corregir el modelo liberal para equilibrar el modelo a favor de las clases populares (RÍOS, 2005). El PT brasileño también es un partido de izquierda que intenta corregir los desequilibrios del sistema liberal (CARDIM DE CARVALHO, 2005).

En el caso mexicano, es posible que se esté desarrollando un régimen de partidos en torno a dos partidos con proyectos distintos, que representen a diferentes sectores de la sociedad. En este tenor, la actual polarización del régimen de partidos mexicano puede tener como efecto que el PAN se defina más claramente como el partido que representa a los sectores más favorecidos por el modelo de apertura. Con el PRD se identificarían los 
sectores perdedores de la apertura. El PRI, en tanto partido catch-all podría disolverse entre estas dos opciones si sigue perdiendo las elecciones.

No obstante, esto no quiere decir que no existan problemas de representatividad en los países que hemos citado. Por ejemplo, en Chile, el sistema electoral binominal no permite que entren pequeños partidos al Congreso, con lo que ha aumentado el porcentaje de votos sin representación (JOIGNANT, LÓPEZ, 2005, p. 67) así como la no-inscripción de los jóvenes (HUNEEUS, 2005, p. 80; OLAVARRÍA, 2003). En México, el umbral inferior del sistema electoral permite el surgimiento de pequeños partidos que encarnan intereses más estrechos, pero el hecho de que se permitan las coaliciones entre partidos, permite la reproducción de pequeños partidos con poca representatividad, que no sobrevivían por sí solos el umbral del 2\% de votos.

Por otra parte, la actuación del Congreso en los últimos años, en especial durante la presidencia de Vicente Fox (2000-2006), ha dado la impresión de que los partidos se conducen con base en intereses de corto plazo, contribuyendo a construir una mala imagen de los partidos. Como lo planteó Weber, instituciones que no tienen responsabilidad comienzan a actuar de manera irresponsable (citado por O’DONNELL, 1996, p. 86). En el antiguo régimen mexicano, el Congreso estuvo totalmente subordinado a la presidencia. Es difícil hacer la transformación de esa situación a la actual en la que el Congreso tiene facultades significativas.

De esta manera, para consolidar el régimen de partidos, el PRI tendría que transformarse en un verdadero partido y abandonar su comportamiento como un partido de Estado que esta momentáneamente fuera del poder. $\mathrm{Al}$ PRD le falta transformarse en un partido con una estructura nacional y un programa coherente; en la actualidad es más un frente de movimientos sociales, en el que cada corriente mantiene distintos proyectos, intereses y dirigencias, que en muchas ocasiones están incluso enfrentadas entre sí; que se nota especialmente a la hora de elegir candidatos (PROUD'HOMME, 2005; COMBES, 2004). Esto demuestra que el PRD no ha hecho lo que hizo el PT con las organizaciones que lo crearon, fundirlas en una estructura institucional nacional; que eventualmente le permitió tener una presencia 
y ganar elecciones nacionales ${ }^{7}$ (TRIGUBOFF, EBERHARDT, MARTIN, 2006; WERNECK VIANNA, 2001).

Por otra parte, el creciente intercambio de personal político entre los principales partidos puede llevar a la confusión del electorado y a un vacío de representatividad del régimen de partidos mexicano. Hemos visto como se han borrado las diferencias ideológicas entre el sector del PRI que acusa a los gobiernos “tecnocráticos” de De la Madrid (1982-88), Salinas (1988-94) y Zedillo (1994-2000) de haber traicionado los fundamentos ideológicos del partido y el PRD. Por otro lado, hemos visto el acercamiento entre los tecnócratas del PRI y el PAN.

\section{La sociedad civil}

Finalmente, es necesario analizar el arraigo de los partidos políticos en la sociedad. Es bastante claro que México siguió la vía de las transiciones que fueron controladas por las elites gubernamentales salientes. La transición nunca escapó de las manos de las elites autoritarias, quienes lograron mantenerlo al nivel electoral. Nunca se organizó una oposición social fuerte que pudiera modificar esta situación, extender las transformaciones al nivel social, descarrilar el proyecto gubernamental, como sucedió en Polonia y Brasil.

De hecho, en México, el proceso de liberalización nunca rebasó la dimensión electoral. El gobierno siempre logró canalizar las fuerzas políticas y sociales por esta vía y a controlar el espacio social. Fue capaz de impedir la emergencia de un movimiento de la sociedad civil. De esta manera, las transformaciones del régimen político mexicano fueron más controladas que negociadas. El gobierno mexicano tuvo la capacidad de mantener el control de la mayoría de las organizaciones de la sociedad civil por la vía de los sindicatos, las organizaciones campesinas y otras organizaciones populares. Con ello logró desmovilizar o desmantelar cualquier tendencia que hubiera implicado el desarrollo de la sociedad civil de manera autónoma y fuera de la dimensión electoral.

Dos momentos claves de esta capacidad del gobierno mexicano : 1. La

${ }^{7}$ Y, en efecto, el PRD aún no tiene presencia en todo el país: por ejemplo: su votación es escasa en el Norte y Occidente del país. 
forma en la que manejó y desmanteló al movimiento sindical independiente, mediante la reforma electoral de 1977 y 2. La forma en que marginalizó al movimiento social alrededor del zapatismo y al propio movimiento zapatista, con las reformas de 1994 y luego 1996.

Durante la primera mitad de la década de los setentas, gran número de sindicatos lograron independizarse del control de las grandes centrales oficialistas $^{8}$, en un amplio movimiento de rechazo al sindicalismo controlado por el Estado, con el beneplácito del gobierno de Echeverría (1970-1976). El sexenio siguiente, el de López Portillo (1976-1982), fue el primer momento en el que se desmanteló a la sociedad civil. En esa época se revirtieron los efectos del movimiento de insurgencia sindical, por medio de la reforma política de 1977, en la que se planteó a la izquierda que la vía para su acción era la de los partidos políticos y que era ilegitimo actuar al interior de las organizaciones sociales. La vía electoral fue abrazada por la mayoría de los grupos de izquierda, lo que si bien es cierto comenzó a debilitar electoralmente al PRI y contribuyó a la democratización por la vía electoral. Por otra parte, debilitó al sindicalismo independiente, que fue en gran parte recuperado por el sindicalismo oficialista (BIZBERG, 2004).

Otro momento clave en el que la democratización fue encauzada hacia la vía electoral sucedió en 1994. En torno al zapatismo, que para mediados del año ya había abandonado la vía armada y se había volcado hacia la organización de la sociedad civil, se estaban aglutinando un importante número de organizaciones civiles, muchas de ellas surgidas a partir del sismo de 1985. No obstante, después del asesinato de Colosio y ante la cercanía de unas elecciones que parecían implicar graves peligros para el país, se negocia una reforma política que ciudadaniza al IFE y que le quita parcialmente al gobierno el control de las elecciones. A partir de este momento se planteó una disyuntiva a las organizaciones de la sociedad civil, seguir construyendo un frente para la organización independiente de la sociedad civil en torno al zapatismo o luchar por una mayor transparencia y el control ciudadano de las elecciones. La creación de Alianza Cívica, quien tomó el liderazgo de esta segunda opción, comprometió a gran parte de la sociedad civil por la vía electoral y marginó al zapatismo. Finalmente, esta cuestión en torno al cual

${ }^{8}$ En especial de la Confederación de Trabajadores de México (CTM) que forma parte del PRI. 
se aglutinaron las asociaciones de la sociedad civil se agotó cuando triunfó el movimiento, una vez que se dio la ciudadanización completa del IFE con la reforma electoral de 1996 y la alternancia en el poder de la presidencia en el año 2000. Por otra parte, muchas de las asociaciones civiles fueron descabezadas cuando el Partido de la Revolución Democrática conquistó el gobierno de la ciudad de México en 1997 y cuando el Partido Acción Nacional ganó la presidencia de la República, como consecuencia de la integración de muchos de los cuadros de las asociaciones civiles al gobierno del Distrito Federal y a la Secretaría de Desarrollo Social Federal (OLVERA, 2003).

Aunque estos dos momentos contribuyeron de manera fundamental a que se diera una transformación política sin rupturas en México, contribuyeron a que esta se produjera casi exclusivamente en el ámbito electoral, que la democratización se limitara a la alternancia en la presidencia de la República. Aunque este logro es considerable, tuvo como efecto que las principales organizaciones de la sociedad civil: sindicatos, organizaciones campesinas, y otras organizaciones populares, quedaran sometidas a los viejos liderazgos, que siguen practicando las viejas formas de control clientelar.

Aún si esta situación tuvo como efecto que la oposición política tomara ventaja de la reciente debilidad del PRI, esto no sucedió a nivel de las organizaciones sociales, que estuvieron y siguen estando en su gran mayoría bajo control de este partido. Por ello, a pesar de que hubo una alternancia en la presidencia de la República en el 2000, la situación de la mayoría de las organizaciones sociales prácticamente no se ha modificado

Son bastante evidentes las consecuencias sobre la posibilidad de afirmar la democracia de acuerdo a las dimensiones que se definieron anteriormente. Por una parte, al lograr canalizar la democratización casi exclusivamente por la vía electoral, se limitó de manera importante el desarrollo autónomo de la sociedad civil. A pesar de que en los últimos años han surgido gran cantidad de asociaciones no gubernamentales dedicadas a numerosas causas (VERDUZCO IGARTÚA, 2005), el sindicalismo autónomo es bastante limitado en comparación con al peso del sindicalismo vinculado al PRI. La mayor de las organizaciones sindicales autónomas, la Unión Nacional de Trabajadores (UNT) agrupa a alrededor de 500,000 trabajadores, alrededor 
del $10 \%$ de la población sindical mexicana ${ }^{9}$. Además, el sindicalismo autónomo está dividido y lleva a cabo una política gremialista, orientada hacia el interior de las empresas, que tiene como consecuencia aislarlo de los sindicatos de los sectores que más han sufrido con la apertura económica, así como de otras organizaciones populares. Todo ello, limita considerablemente su capacidad de acción (BENSUSÁN, 2005, p. 130). En el caso del ámbito campesino, las organizaciones autónomas son aún menos numerosas (RUBIO, 1996). Por su parte, las organizaciones que dejaron el PRI y se aliaron al PRD conservan muchas de las mismas características corporativas y clientelares. A pesar de que la política social del PRD refleja una relación innovadora entre el gobierno y los sectores más pobres de la población, en lo que respecta a la relación con las organizaciones que representan a estos sectores, mantiene una relación en la que la política prima por encima del fortalecimiento de la sociedad civil (ZERMEÑO, 2004) y que puede considerarse como netamente clientelar.

De esta manera, si vemos a la democratización mexicana en una perspectiva comparada, se parece más al caso chileno en la que se desmovilizó al movimiento de pobladores para preparar el plebiscito que derrotó a Pinochet, que a la democratización brasileña en la que el sindicalismo jugó un papel fundamental y logró renovarse totalmente, al grado de que fundó un partido profundamente enraizado en la sociedad civil. El hecho de que la democratización brasileña implicó una profunda transformación de la sociedad civil, explica que el PT, partido que surge con base en el dinamismo y la modernidad del sindicalismo, haya logrado inventar el presupuesto participativo, para intentar transformar la política brasileña, destruyendo la que ha sido su base principal desde el periodo varguista: el clientelismo (ABERS, 2000; ARVITZER, 2002; GOIRAND, 2002; KOWARICK, SINGER, 1997).

\section{Consideraciones finales}

Para estas consideraciones finales, es necesario regresar al esquema de los regímenes de partido y a las variables que los definen. Los distintos regímenes

\footnotetext{
${ }^{9}$ Este cálculo de ambas cantidades es muy discutible. No obstante, no existen datos alternativos verdaderamente confiables.
} 
partidistas dependen tanto del nivel de institucionalización de los partidos, de la representatividad del sistema partidista y del grado de organización de la sociedad civil. En América Latina tenemos claramente dos casos contrastantes. En Brasil hay una fuerte organización de la sociedad civil que se congregó en torno al nuevo sindicalismo, a las numerosas organizaciones sociales que intervinieron en la discusión de la Constitución de 1988 y en el Partido de los Trabajadores (CHAVES TEXEIRA, DAGNINO, ALMEIDA SILVA, 2002). Esto ha dado lugar a varias formas de democracia participativa en ese país. Pero, cómo es bien sabido, el régimen de partidos políticos brasileño ha sido débil y aún está poco consolidado, a pesar de que parecen estarse arraigando dos bloques partidistas estables: el PT y el PSDB. En contraste, la democratización por la vía electoral en México ha dado lugar a un régimen de partidos políticos que parece relativamente estable ${ }^{10}$, aunque fuertemente cuestionado en su representatividad. Por el otro lado, existe una sociedad civil relativamente débil, en la medida en que las principales organizaciones populares (sindicatos, organizaciones campesinas) son poco autónomas y representativas de los actores políticos y el sector de las ONG's parece estarse debilitando. En términos del esquema de regímenes partidistas, mientras que Brasil se ubica entre un régimen clientelar y la democracia participativa, con tendencia a avanzar hacia esta última, México se halla entre el corporativismo y la partidocracia.

La pregunta de hacia donde va a avanzar el régimen partidista mexicano depende de varias cuestiones. Es posible plantear tres distintos escenarios: 1. Es posible que se consolide el régimen de partidos en México y que se avance hacia una democracia más representativa, si dos de los partidos políticos principales, el PRI y el PRD, rebasan su crisis actual y sus divisiones internas y logran transformarse y renovar sus vínculos con las organizaciones sociales. Parece que el régimen de partidos de Brasil está avanzando en esta dirección, en la medida en que la propia sociedad civil está influyendo en la consolidación e institucionalización del régimen de partidos. La solidez y disciplina del PT y su enraizamiento en la sociedad civil han influido en este proceso. El régimen partidista mexicano podría avanzar en un proceso similar

\footnotetext{
${ }^{10} \mathrm{~A}$ pesar de la crisis por la que están pasando los partidos en la actualidad, a raíz de las tan contestadas elecciones de 2006.
} 
al brasileño, aunque de signo contrario porque va de los partidos hacia la sociedad civil. La actual estabilidad del régimen de partidos mexicano podía entonces evolucionar hacia su eventual transformación y consolidación, lo que a su vez podría llevar al fortalecimiento de la sociedad civil. No obstante, este es un escenario poco probable dada la poca voluntad política que han mostrado los tres partidos políticos principales para llevar a cabo acciones que le den mayor autonomía a la sociedad civil.

Los dos escenarios más probables son: 2. el de la estabilización del régimen, a pesar de que los partidos políticos están poco arraigados en la sociedad civil. Esto sería posible si logra gobernar de manera eficaz, como nos lo demuestra el caso chileno. Un régimen político puede conservarse mientras el gobierno sea eficiente en términos económicos y tenga los mecanismos para tomar en cuenta los intereses de los grupos que no tienen representación política, entre ellos los sectores más marginados de la sociedad. Esto permite que el gobierno les responda con base en políticas sociales que reconozcan sus necesidades más imperiosas, como lo ha hecho el partido socialista chileno desde la administración de Lagos. 3. Pero también es posible que la falta de organización de la sociedad civil agrave la crisis del régimen de partidos. Y que esta falta de canales para la expresión de las demandas sociales, este vacío de representación, lleve a los individuos a sentirse atraídos por las soluciones populistas; lo que ya ha sucedido en varios países de América Latina, tanto en el pasado, como en el presente. 


\section{Referencias Bibliográficas}

ABERS, Rebeca. Inventing local democracy: glassroots politics in Brazil. Boulder, Lynne Rienner, 2000.

ANGELL, Alan. Party change in Chile in comparative perspective. Universidad de Oxford, 2004. manuscrito.

ARVITZER, Leonardo. Sociedad civil, espacio público y poder local: un análisis del presupuesto participativo en Belo Horizonte y Porto Alegre. En: DAGNINO, Evelina. (Coord.). Sociedad civil, esfera publica y democratización en América Latina. Brasil: Unicamp-FCE, México, 2002.

BARRETT, Patrick S. Chile's transformed party system and future of democratic Stability. Journal of Latin American Studies and World Affairs, v. 42, n. 3, otoño. 2000.

BENSUSÁN, Graciela. Renovación sindical y democracia: los límites de la alternancia. En: AZIZ, Alberto; SÁNCHEZ, Jorge Alonso (Coord.). El estado mexicano: herencias y cambios. Sociedad civil y diversidad. Tomo III. México: CIESAS-Porrua, 2005.

BIZBERG, Ilán. La transformation politique du Mexique: fin de l'ancien régime et apparition? Du nouveau. Critique Internationale, Paris, n. 19, Presses de Sciences Po, abril. 2003.

. Las transformaciones del poder político en México. Revista Mexicana de Sociología, México, UNAM, v. 61, n. 3, 1999.

. Auge y decadencia del corporativismo mexicano. En: BIZBERG, Ilán; MEYER, Lorenzo. Una historia contemporánea de México. Tomo 1. Transformaciones y permanencias. México, Océano, 2004.

CARDIM DE CARVALHO, Fernando. Lula's government in Brasil: a new left or the old populism? Manuscrito sometido a la revista Tiers Monde, 2005.

CHAVES TEXEIRA, Ana Claudia; DAGNINO, Evelina; ALMEIDA SILVA, Cecília. La constitución de la sociedad civil en Brasil. En: DAGNINO, Evelina (Coord.). Sociedad civil, esfera publica y democratización en América Latina. Brasil: Unicamp-FCE, México, 2002. 
COMBES, Hélène. Élections internes et transition démocratique. Le cas du Parti de la révolution démocratique au Mexique. Problèmes d'Amérique Latine, Institut Choiseul pour la Politique Internationale et la Geoeconomie, n. 54, otońo. 2004.

COPPEDGE, Michael. The evolution of Latin American Party Systems. En: MAINWARING, Scott; VALENZUELA, Arturo. Politics, Society and Democracy, Westview Press, Boulder, 1998.

DIAMOND, Larry; LINZ, Juan J.; Seymour Martin, LIPSET. Democracy in developing countries: comparing experiences with democracy. Lynne Rienner, Boulder, 1995.

GOIRAND, Camille. La démocratie participative au Brésil: les expériences de budgets municipaux participatifs. Cahiers du GELA.IS, Paris, n. 2, L'Hartmattan, 2002.

HABERMAS, Jürgen. Droit et democratie. Entre faits en normes. Paris: Gallimard, 1997.

HUNEEUS, Carlos. Chile: a system frozen by elite interests. Electoral System Design, Stockholm, IDEA, Handbook Series, 2005.

JOIGNANT, Alfredo; LOPEZ, Miguel Angel. Le comportement électoral au Chili: paradoxes et présomptions sur la continuité ou la rupture de l'orientation du vote. Problèmes d'Amérique Latine, Institut Choiseul pour la Politique Internationale et la Géoéconomie, n. 56, primavera. 2005.

KINZO, Maria D’Alva Gil. Transitions: Brazil. En: GARRETÓN, Manuel Antonio; NEWMAN, Edward. Democracy in Latin America. (Re) constructing political society. Tokio-NY-Paris: UN University Press, 2001.

KOWARICK, Lucio.; SINGER, Andre. La experiencia del partido de los trabajadores en la alcaldía de San Pablo. América Latina Hoy, Revista de Ciencias Sociales. Universidad Complutense de Madrid, n. 15, abril. 1997.

LACLAU, Ernesto. La razón populista. México, Fondo de Cultura Económica, 2006. 
MAINWARING, Scott; SCULLY, Timothy R. (Eds.). Building democratic institutions: party systems in Latin America. California: Stanford University Press, 1995.

MAINWARING, Scott. Rethinking party systems in the third wave of democratization. The case of Brazil. Stanford: Stanford University Press, 1999.

O'DONNELL, Guillermo. Horizontal accountability in new democracies. Journal of Democracy, v. 9, n. 3, julio. 1998.

. Ilusiones sobre la consolidación. Nueva Sociedad, n. 144, jul./ago. 1996.

O’DONNELL, Guillermo; SCHMITTER, Philippe C. Transitions from authoritarian rule. Tentative conclusions about uncertain democracies. Baltimore and London: Johns Hopkins, 1986.

O'DWYER, Conor. Runaway state building. How political parties shape states in postcommunist eastern Europe. World Politics, n. 5, julio. 2004.

OLAVARRÍA, Margot. Protected neoliberalism, perverse institutionalization and the crisis of representation in postdictatorship Chile. Latin American Perspectives, n. 132, sept. 2003.

OLVERA, Alberto Javier. Movimientos sociales prodemocráticos y esfera pública en México: el caso de Alianza Cívica. En: OLVERA, Alberto Javier. Sociedad civil, esfera pública y democratización en América latina: México. México: Univ. Veracruzana y FCE, 2003.

PROUD’HOMME, J.-F. Le parti de la Révolution Démocratique: une institutionnalisation difficile. Problèmes d'Amérique Latine, Institut Choiseul pour la Politique Internationale et la Géoéconomie, n. 55, invierno. 20042005. 
PNUD. La Democracia en América Latina. Hacia una democracia de ciudadanas y ciudadanos. N.Y.: PNUD, 2004.

PRZEWORSKI, Adam. Some problems in the study of the transition to democracy. Working Papers, Washington, n. 61, Wilson Center (Latin American Program), s/fecha.

RÍOS, Guillermo Larrain. Croissance rapide et inégalités extrêmes au Chili. Problèmes d'Amérique Latine, Institut Choiseul pour la Politique Internationale et la Géoéconomie, n. 56, primavera. 2005.

RUBIO, Blanca. Las organizaciones independientes en México: semblanzas de las opciones campesinas ante el proyecto neoliberal. En: GRAMONT, H. C. Neoliberalismo y organización social en el campo mexicano. México: UNAM y Plaza y Valdez editores, 1996.

TIRONI, Eugene; AGÜERO, Felipe. Chili: quel avenir pour le nouveau paysage politique? Problèmes d'Amérique Latine, Paris, La Documentation Française, n. 35, oct./dec. 1999.

TOCQUEVILlE, Alexis. De la democratie en Amérique. Paris: Flammarion, 1981.

TOURAINE, Alain. Qu'est-ce que la democratie? Paris: Fayard, 1994.

TRIGUBOFF, Matias; EBERHARDT, Maria Laura; MARTIN, Alessandro. Los partidos de izquierda en el cono sur: el Partido de los Trabajadores, el Frente Amplio y el Partido Socialista de Chile en perspectiva comparada. Manuscrito presentado en LASA. Puerto Rico: 2006.

VERDUZCO IGARTÚA, Gustavo. Las organizaciones solidarias en México. En: BIZBERG, Ilán; MEYER, Lorenzo. Una historia contemporánea de México. Tomo 2. México: Actores, Océano, 2005. 
WELDON, Jeffrey. Mexico: democratization through electoral reform. En: REYNOLDS, Andrew; REILLY, Ben; ELLIS, Andrew. Electoral System Design. Stockholm: IDEA, Handbook Series, 2005.

WERNECK VIANNA, Luiz. La izquierda y los quince años de la transición en Brasil. Estudios Sociológicos, n. 55, enero/abril. 2001.

ZERMEÑO, Sergio. La participación ciudadana bajo los gobiernos peredistas del Distrito federal (1997-2003). En: ZICCARDI, Alicia. Participación ciudadana y políticas sociales en el ámbito local. México: IIS-UNAM, 2004. 